\title{
NEW STUDY ON FORCE TRANSDUCER'S TEMPERATURE BEHAVIOUR
}

\author{
Kui Gan ${ }^{1}$, Hong Jiang ${ }^{2}$, Hongjiang Chen ${ }^{3}$, Hao Zhang ${ }^{4}$, William Huang ${ }^{5}$ \\ ${ }^{1}$ Hunan Institute of Metrology and Test, Changsha, China, fancygk@163.com \\ ${ }^{2}$ Shanghai Institute of Quality Inspection and Technical Research, Shanghai, China, jianghong@sqi.org.cn \\ ${ }^{3}$ Hunan Institute of Metrology and Test, Changsha, China, 31862083@qq.com \\ ${ }^{4}$ Hunan Institute of Metrology and Test, Changsha, China,664074026@qq.com \\ ${ }^{5}$ GTM China Office, Shanghai, China, william.huang@gtmchina.cn
}

\begin{abstract}
:
This paper describes a new study about the temperature behaviour of force transducers. A special force transducer with a PT100 for temperature measuring was developed by GTM. The curve of heating was created, and test data indicates the time for attaining the stable temperature. Meanwhile the different sensitivity of the transducer under different temperatures was obtained, thus the temperature effect on characteristic value per $10 \mathrm{~K}$ (so-called $T K c$ ) was calculated. At the end, the correction of force transducer at different temperatures was made by the $T K c$ factor of temperature.
\end{abstract}

Keywords: force transducer; temperature measurement; temperature effect

\section{INTRODUCTION}

As is well known, the transducer temperature is not exactly the same as the room temperature during calibration. ISO 376:2011 [1] states that "sufficient time shall be allowed for the force-proving instrument to attain a stable temperature", but there is no guarantee that the temperature of the transducer's whole body has reached room temperature, even after several hours. Normally the temperature of the surface of the transducer will then be the same as room temperature, but the temperature inside the transducer is unknown.

Additionally, every manufacturer of transducers provides data sheets specifying $T K c$ (temperature effect on characteristic value per $10 \mathrm{~K}$ ) and $T K_{0}$ (temperature effect on zero signal per $10 \mathrm{~K}$ ) in their catalogues or instruction manuals. However, it is not easy for the end user to know if this is true or if something may change after several years' usage of the transducer.

In the past some similar studies $[2,3]$ have been done and the papers also describe the temperature behaviour of the transducer. They measured the temperature of the chamber or the laboratory, but the temperature of the transducer was never measured directly. All the data of temperature mentioned were the room temperature.

Therefore, it makes sense to do a new study with special design of the transducer with temperature measurement on its body.

\section{EQUIPMENT}

A special transfer standard force transducer was designed and manufactured by GTM based on the type KTN-D. A PT100 sensor was attached inside this transducer on the elastomer, as shown in Figure 1.

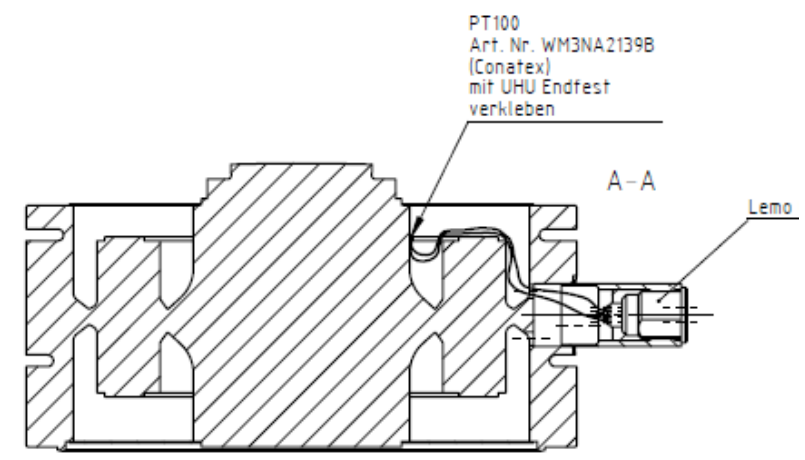

Figure 1: PT100 inside the transducer

The transducer has two measurement circuits: one is for force $\left(F_{z}\right)$ and the other is for temperature (PT100), as in Figure 2.

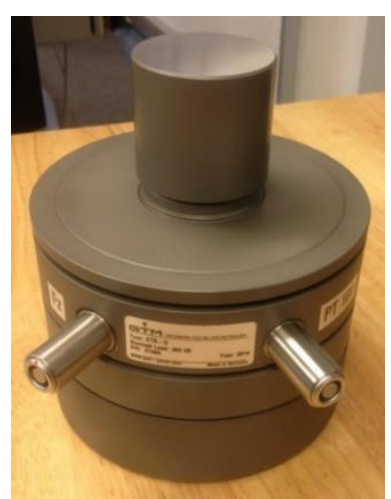

Figure 2: Force transducer with PT100 inside 
This is a transfer standard force transducer of $300 \mathrm{kN}$ capacity, Class 00 according to ISO 376. We use a $300 \mathrm{kN}$ deadweight machine with $U_{\text {rel }} \leq 0.005 \%(k=2)$ in the force laboratory. The amplifier is DMP41 for force and a monitor for PT100. The uncertainty of the temperature measurement is $U_{\text {rel }}=0.5^{\circ} \mathrm{C}(k=2)$.

\section{PROCEDURE}

We have done two calibration tests, with the transducer and amplifier in the same room.

\subsection{Temperature Measurement Only - Without Load}

1. At the beginning, the room temperature is around $15{ }^{\circ} \mathrm{C}$. Increase the temperature to $20^{\circ} \mathrm{C}$ using the room's air conditioning. Record the values of both the PT100 and the thermometer every hour for nine hours.

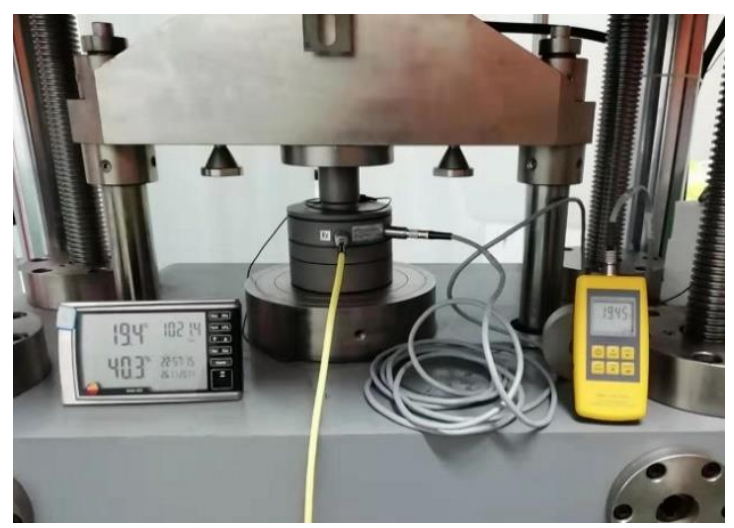

Figure 3: Temperature measurement

2. At the beginning, the room temperature is around $15{ }^{\circ} \mathrm{C}$. Increase the temperature to $25^{\circ} \mathrm{C}$ using the room's air conditioning. Record the values of both the PT100 and the thermometer every hour for nine hours.

\subsection{Calibration Test With Load}

\subsubsection{Test from $15{ }^{\circ} \mathrm{C}$ to $25^{\circ} \mathrm{C}$}

1. Under temperature of $15^{\circ} \mathrm{C}$, calibrate the transducer according to ISO 376, but without change position. That means no rotation position. Pre-load up to $300 \mathrm{kN}$. Three calibration series, and the calibration steps are: $30 \mathrm{kN}, 50 \mathrm{kN}, 100 \mathrm{kN}$, $150 \mathrm{kN}, 200 \mathrm{kN}, 250 \mathrm{kN}$ and $300 \mathrm{kN}$. The holding time of each step is $30 \mathrm{~s}$.

2. Under temperature of $25^{\circ} \mathrm{C}$, test the transducer, according to ISO 376, but without change position. That means no rotation position. Pre-load up to $300 \mathrm{kN}$. Three calibration series, and the calibration steps are: $30 \mathrm{kN}, 50 \mathrm{kN}, 100 \mathrm{kN}$, $150 \mathrm{kN}, 200 \mathrm{kN}, 250 \mathrm{kN}$ and $300 \mathrm{kN}$. The holding time of each step is $30 \mathrm{~s}$.

\subsubsection{Test from $10{ }^{\circ} \mathrm{C}$ to $20^{\circ} \mathrm{C}$}

1. Under temperature of $10{ }^{\circ} \mathrm{C}$, test the transducer according to ISO 376, but without change position. That means no rotation position. Pre-load up to $300 \mathrm{kN}$. Three calibration series, and the calibration steps are: $30 \mathrm{kN}, 50 \mathrm{kN}, 100 \mathrm{kN}$, $150 \mathrm{kN}, 200 \mathrm{kN}, 250 \mathrm{kN}$ and $300 \mathrm{kN}$. The holding time of each step is $30 \mathrm{~s}$.

2. Under temperature of $20^{\circ} \mathrm{C}$, test the transducer according to ISO 376, but without change position. That means no rotation position. Pre-load up to $300 \mathrm{kN}$. Three calibration series, and the calibration steps are: $30 \mathrm{kN}, 50 \mathrm{kN}, 100 \mathrm{kN}$, $150 \mathrm{kN}, 200 \mathrm{kN}, 250 \mathrm{kN}$ and $300 \mathrm{kN}$. The holding time of each step is $30 \mathrm{~s}$.

Collect all the data.

\section{DATA ANALYSIS}

The data from test 3.1 is plotted in Figure 4 and Figure 5.

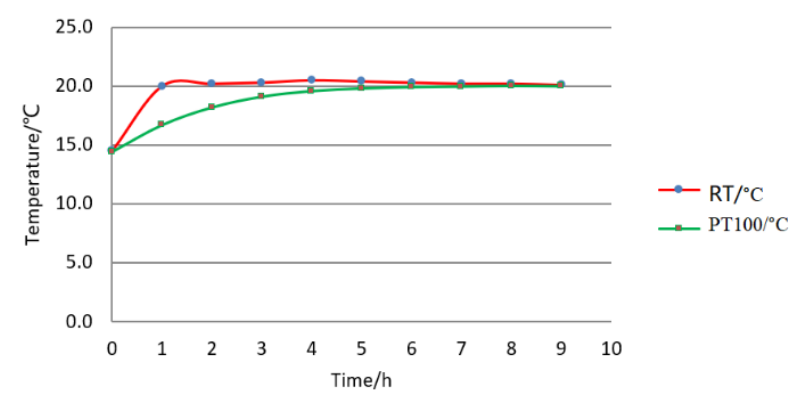

Figure 4: Temperature measurement 1 of 3.1

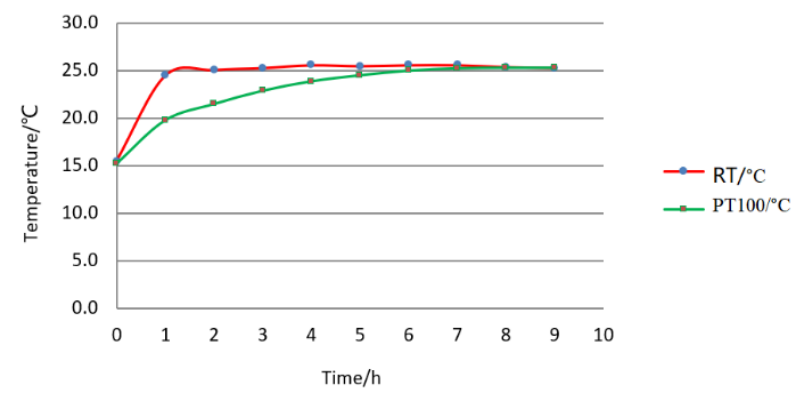

Figure 5: Temperature measurement 2 of 3.1

Both curves show that it takes around eight hours for the transducer body (PT100) to reach room temperature (RT).

The data from test 3.2.1 is given in Table 1 and Table 2, including the repeatability of the transducer $\left(b^{\prime}\right)$.

Table 1: Test at $15^{\circ} \mathrm{C}\left(\mathrm{PT} 100=15.24{ }^{\circ} \mathrm{C}\right)$

\begin{tabular}{|c|c|c|c|c|c|}
\hline $\boldsymbol{F}$ & Run 1 & Run 2 & Run 3 & Mean & $\boldsymbol{b}^{\prime}$ \\
\hline $\mathbf{k N}$ & $\mathbf{m V / V}$ & $\mathbf{m V} / \mathbf{V}$ & $\mathbf{m V} / \mathbf{V}$ & $\mathbf{m V / V}$ & $\mathbf{\%}$ \\
\hline 30 & 0.200076 & 0.200074 & 0.200067 & 0.200072 & 0.004 \\
\hline 50 & 0.333453 & 0.333453 & 0.333450 & 0.333452 & 0.001 \\
\hline 100 & 0.666888 & 0.666883 & 0.666882 & 0.666884 & 0.001 \\
\hline 150 & 1.000302 & 1.000298 & 1.000288 & 1.000296 & 0.001 \\
\hline 200 & 1.333701 & 1.333690 & 1.333680 & 1.333690 & 0.002 \\
\hline 250 & 1.667053 & 1.667045 & 1.667040 & 1.667046 & 0.001 \\
\hline 300 & 2.000347 & 2.000333 & 2.000325 & 2.000335 & 0.001 \\
\hline
\end{tabular}


Table 2: Test at $25^{\circ} \mathrm{C}\left(\mathrm{PT} 100=25.35^{\circ} \mathrm{C}\right)$

\begin{tabular}{|c|c|c|c|c|c|}
\hline $\boldsymbol{F}$ & Run 1 & Run 2 & Run 3 & Mean & $\boldsymbol{b}^{\prime}$ \\
\hline $\mathbf{k N}$ & $\mathbf{m V / V}$ & $\mathbf{m V} / \mathbf{V}$ & $\mathbf{m V} / \mathbf{V}$ & $\mathbf{m V} / \mathbf{V}$ & $\boldsymbol{\%}$ \\
\hline 30 & 0.200105 & 0.200111 & 0.200111 & 0.200109 & 0.003 \\
\hline 50 & 0.333514 & 0.333535 & 0.333526 & 0.333525 & 0.006 \\
\hline 100 & 0.667014 & 0.667050 & 0.667038 & 0.667034 & 0.005 \\
\hline 150 & 1.000502 & 1.000549 & 1.000533 & 1.000528 & 0.005 \\
\hline 200 & 1.333968 & 1.334027 & 1.334005 & 1.334000 & 0.004 \\
\hline 250 & 1.667377 & 1.667439 & 1.667410 & 1.667409 & 0.004 \\
\hline 300 & 2.000722 & 2.000792 & 2.000760 & 2.000758 & 0.003 \\
\hline
\end{tabular}

This transducer was made according to Class 00 of ISO 376. The repeatability in Class 00 is $b^{\prime}<0.025 \%$. We can see that $b^{\prime}$ at $15^{\circ} \mathrm{C}$ is $\leq 0.004 \%$, and $b^{\prime}$ at $25{ }^{\circ} \mathrm{C}$ is $\leq 0.006 \%$, meeting Class 00 of ISO 376.

According to the Chinese calibration guideline JJG 144 [4], the repeatability is $0.01 \%$ and $0.03 \%$ (Class 0.01 and Class 0.03).

The data of Table 1 and Table 2 are compared, thus $T K c$ was calculated as in Table 3.

Table 3: Calculation of $T K c$

\begin{tabular}{|c|c|c|c|}
\hline $\boldsymbol{F}$ & $\mathbf{m V} / \mathbf{V}$ & $\mathbf{m V} / \mathbf{V}$ & $\boldsymbol{T K} \boldsymbol{c}$ \\
\hline $\mathbf{k N}$ & $\begin{array}{c}\text { Ave at } \\
\mathbf{1 5 . 2 4}^{\circ} \mathbf{C}\end{array}$ & $\begin{array}{c}\text { Ave at } \\
\mathbf{2 5 . 3 5}^{\circ} \mathbf{C}\end{array}$ & \% / 10 K \\
\hline 30 & 0.200072 & 0.200109 & 0.018 \\
\hline 50 & 0.333452 & 0.333525 & 0.022 \\
\hline 100 & 0.666884 & 0.667034 & 0.022 \\
\hline 150 & 1.000296 & 1.000528 & 0.023 \\
\hline 200 & 1.333690 & 1.334005 & 0.023 \\
\hline 250 & 1.667046 & 1.667409 & 0.022 \\
\hline 300 & 2.000335 & 2.000758 & 0.021 \\
\hline
\end{tabular}

$T K C$ is one specificity of the transducer with strain-gauge technology. Every manufacturer provides this data in the product catalogue. This transducer of KTN-D also gives the value of $T K c=0.02 \% / 10 \mathrm{~K}$ in the datasheet. Now we can see the value by the test is $0.023 \%$ (maximum) and $0.018 \%$ (minimum).

From Table 3, the average value of $T K c$ is taken as $0.022 \% / 10 \mathrm{~K}$.

The data from test 3.2.2 were collected and compared as shown in Table 4.

As mentioned, $T K C$ is $0.022 \% / 10 \mathrm{~K}$ for this transducer according to test 3.2.1. Using this value, its performance at a temperature of $11.49^{\circ} \mathrm{C}$ is corrected to an expected performance at a temperature of $19.53{ }^{\circ} \mathrm{C}$, with the results given in Table 5 .
Table 4: Deviation from test 3.2.2

\begin{tabular}{|c|c|c|c|}
\hline $\boldsymbol{F}$ & $\mathbf{~ m V / V}$ & $\mathbf{~} \mathbf{V} / \mathbf{V}$ & Deviation \\
\hline $\mathbf{k N}$ & at $\mathbf{1 1 . 4 9}^{\circ} \mathbf{C}$ & at $^{\mathbf{1 9 . 5 3}}{ }^{\circ} \mathbf{C}$ & $\%$ \\
\hline 30 & 0.200061 & 0.200094 & 0.016 \\
\hline 50 & 0.333434 & 0.333492 & 0.017 \\
\hline 100 & 0.666842 & 0.666969 & 0.019 \\
\hline 150 & 1.000236 & 1.000422 & 0.019 \\
\hline 200 & 1.333607 & 1.333859 & 0.019 \\
\hline 250 & 1.666944 & 1.667253 & 0.019 \\
\hline 300 & 2.000219 & 2.000583 & 0.018 \\
\hline
\end{tabular}

Table 5: Corrected value

\begin{tabular}{|c|c|c|}
\hline $\boldsymbol{F}$ & $\mathbf{~} \mathbf{V} / \mathbf{V}$ & $\mathbf{~} \mathbf{V} / \mathbf{V}$ \\
\hline $\mathbf{k N}$ & at $\mathbf{1 1 . 4 9}^{\circ} \mathbf{C}$ & corrected to $19.53^{\circ} \mathbf{C}$ \\
\hline 30 & 0.200061 & 0.200096 \\
\hline 50 & 0.333434 & 0.333493 \\
\hline 100 & 0.666842 & 0.666960 \\
\hline 150 & 1.000236 & 1.000413 \\
\hline 200 & 1.333607 & 1.333843 \\
\hline 250 & 1.666944 & 1.667239 \\
\hline 300 & 2.000219 & 2.000573 \\
\hline
\end{tabular}

Now the corrected and measured values were compared, with the calculated deviations given in Table 6. The two curves are also shown in Figure 6.

Table 6: Deviations between corrected and measured values

\begin{tabular}{|c|c|c|c|}
\hline $\boldsymbol{F}$ & $\mathbf{m V} / \mathbf{V}$ & $\mathbf{m V} / \mathbf{V}$ & Deviation \\
\hline $\mathbf{k N}$ & $\begin{array}{c}\text { corrected to } \\
\mathbf{1 9 . 5 3}{ }^{\circ} \mathbf{C}\end{array}$ & $\begin{array}{c}\text { measured at } \\
\mathbf{1 9 . 5 3}^{\circ} \mathbf{C}\end{array}$ & $\mathbf{\%}$ \\
\hline 30 & 0.200096 & 0.200094 & -0.001 \\
\hline 50 & 0.333493 & 0.333492 & 0.000 \\
\hline 100 & 0.66696 & 0.666969 & 0.001 \\
\hline 150 & 1.000413 & 1.000422 & 0.001 \\
\hline 200 & 1.333843 & 1.333859 & 0.001 \\
\hline 250 & 1.667239 & 1.667253 & 0.001 \\
\hline 300 & 2.000573 & 2.000583 & 0.000 \\
\hline
\end{tabular}

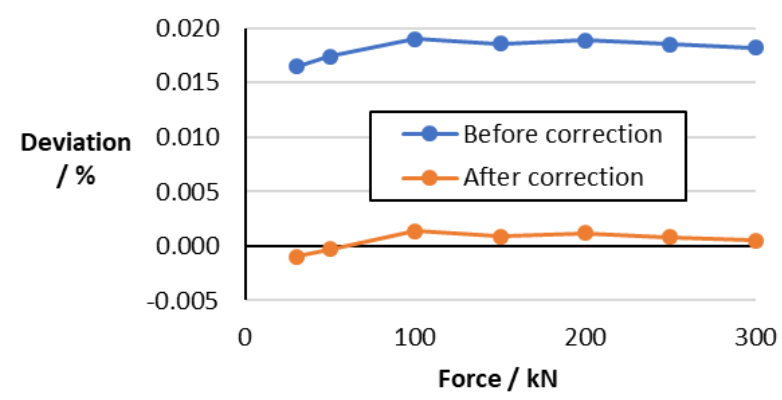

Figure 6: Deviation before correction vs after correction 
The value of after correction is nearly the same as the measurement at $19.53{ }^{\circ} \mathrm{C}$ (the deviation is $-0.001 \%$ ), meaning that the value of $T K C$ is reliable.

Other corrections have also been performed between different temperatures. For a correction at $15.24{ }^{\circ} \mathrm{C}$ based on the measurement value at $11.49^{\circ} \mathrm{C}$, the deviation between the corrected value and the measured value is around $0.003 \%$.

\section{SUMMARY}

This special transducer helps to prove the description in ISO 376 about enough time: around eight hours should be suitable. Indeed, the Chinese calibration guideline JJG 144 [4] also suggests that the time which the transducer put at the laboratory is "more than eight hours". For the transducer of high accuracy class, any time less than eight hours is not recommended.

The temperature behaviour of each force transducer is given by its value of $T K c$. Therefore, the data by the manufacturer should be considered by the user during the calibration. At different room temperatures, the value of $T K c$ can be used to make corrections.

The deviation between the value after correction and measurement directly is same or less than the value of repeatability.

\section{REFERENCES}

[1] ISO 376, Metallic materials - Calibration of force proving instruments used for the verification of uniaxial testing machines, 2011.

[2] D. Röske, "The influence of temperature and humidity on the creep of torque transducers", IMEKO $23^{\text {rd }}$ TC3, $13^{\text {th }}$ TC5 and 4th TC22 International Conference, Helsinki, Finland, 30 May to 1 June 2017.

[3] Min-Seok Kim, "Simultaneous determination of temperature and humidity sensitivity coefficients of torque transfer standards in ambient conditions", IMEKO $23^{\text {rd }}$ TC3, $13^{\text {th }}$ TC5 and 4th TC22 International Conference, Helsinki, Finland, 30 May to 1 June 2017.

[4] JJG 144, Verification Regulation for Standard Dynamometers, SAQSIQ, China, 2007. 